\title{
Hepatic and Intestinal Multidrug Resistance-Associated Protein 2: Transcriptional and Post-transcriptional Regulation by Xenobiotics
}

\author{
Maite R. Arana, Guillermo N. Tocchetti, \\ Juan P. Rigalli, Aldo D. Mottino, Fabiana García and \\ Silvina S.M. Villanueva
}

Additional information is available at the end of the chapter

http://dx.doi.org/10.5772/64755

\begin{abstract}
We are daily exposed to a large number of pharmacological drugs, environmental pollutants, and natural toxins, which represent a potential toxic insult. The organism possesses a sophisticated system of detoxification particularly expressed in the liver, intestine, and kidney. This system consists of intracellular biotransformation enzymes that convert the toxins into more hydrophilic derivatives followed by their elimination through membrane transporters. Multidrug resistance-associated protein 2 (MRP2, $A B C C 2)$ is an important member of the ATP-binding cassette (ABC) superfamily of transporters localized at the apical membrane of polarized cells, such as hepatocytes, enterocytes, and renal tubular cells. MRP2 is proposed as a major actor in the elimination of endo- and xenobiotics, mainly conjugated with glucuronic acid, glutathione, and sulfate. The small intestine and the liver constitute relevant detoxification organs expressing MRP2 and therefore preventing absorption and promoting the hepatobiliary clearance of xenobiotics. MRP2 expression and/or function can be modulated by therapeutic drugs, herbal products, dietary compounds, and environmental pollutants. Consequently, MRP2 modulation could cause changes in tissue exposure, with potential toxicological and pharmacological consequences. This chapter reviews the information available on the role of hepatic and intestinal MRP2 in detoxification processes, and their regulation by xenobiotics, considering in particular its toxicological relevance.
\end{abstract}

Keywords: MRP2, intestine, liver, detoxification, clearance, toxicity 


\section{Introduction}

\subsection{Detoxification of xenobiotics}

Most organisms are daily exposed to a large number of different xenobiotics, such as therapeutic drugs, environmental pollutants, and natural toxins. The major routes of exposure to these chemicals comprise incorporation with the diet, inhalation or absorption through the skin. Preservation of health depends largely on the body's ability to eliminate these harmful substances. In this regard, the organism possesses a sophisticated system of detoxification mainly expressed in organs such as the liver, intestine, and kidney. The detoxification process consists of intracellular biotransformation enzymes that neutralize the toxins and membrane transporters for their subsequent elimination from the cell. The biotransformation process is carried out by the same biochemical machinery that metabolizes endogenous compounds, often of similar chemical structure. Even though a compound can be excreted without undergoing any change, it is usually converted by biotransformation enzymes into a more hydrophilic derivative prior to elimination. The biotransformation reactions are carried out by phase I enzymes such as cytochrome P450 (CYP) members and by phase II conjugating enzymes such as glutathione S-transferase (GST; EC 2.5.1.18), UDP-glucuronosyltransferase (UGT; EC 2.4.1.17), and sulfotransferase (SULT; EC 2.8.2.) [1, 2]. Phase I enzymes usually act in tandem with phase II enzymes, which ultimately results in incorporation of anionic groups into the xenobiotic molecule. The hydrophilic derivatives can be excreted from the cells by phase III or membrane transport systems, with the anionic groups acting as affinity markers for a series of transporters of the multidrug resistance-associated protein (MRP) family. These proteins are members of the ATP-binding cassette $(\mathrm{ABC})$ drug efflux transporters and mediate the active extrusion of biotransformation products for their subsequent elimination from the body [1, 2]. Direct elimination of xenobiotics without suffering any biotransformation is also possible and is denominated "phase 0 metabolism" [3].

What follows is a description of the role of the multidrug resistance-associated protein 2 (MRP2, ABCC2) as an important component of the $\mathrm{ABC}$ family involved in xenobiotic disposition by liver and intestine.

\subsection{Multidrug resistance-associated protein 2 and its role in the detoxification of xenobiotics}

MRP2 structure consists of a large core segment, containing two cytosolic nucleotide-binding domains (NBDs), two membrane-spanning domains (MSDs), and a linker segment L1, shared by other $\mathrm{ABC}$ members. Additionally, MRP2 contains a third $\mathrm{NH}_{2}$-terminal membranespanning domain MSD0, also called terminal transmembrane domain, with five transmembrane helices resulting in an extracellular $\mathrm{NH}_{2}$-terminus and an intracellular linker segment 0 (L0) (Figure 1) [4]. MRP2 is characteristically expressed at the apical membrane of polarized cells such as hepatocytes, enterocytes, and renal tubular cells [4-6], where it plays a primary role in the elimination of specific compounds. Particularly, the highest concentration of this transporter is found in the liver and intestine [7], two organs playing a prominent role in xenobiotic detoxification commonly known as "first-pass metabolism and clearance". Protein expression of MRP2 is highest in enterocytes of the proximal small intestine, decreasing in 
direction to the terminal ileum [8], gradient shared with the expression of phase II metabolizing enzymes such as GST and UGT $[9,10]$, thus suggesting that metabolism and transport processes may act coordinately. In the liver, the major biotransformation organ, MRP2 is abundantly expressed in the bile canalicular membranes of the hepatocyte [11], where it plays a role in bile formation through secretion of endogenous substrates such as glutathione (GSH) and glutathione conjugates. Canalicular MRP2 also constitutes the main route of elimination of xenobiotics conjugated with GSH, sulfate or glucuronic acid [12]. Similarly, immunohistochemical analysis in normal rat liver demonstrated that UGTs and rMrp2 are localized in the same regions [13, 14], also indicating that they may work in cooperation. MRP2 in either localization contributes significantly to disposition of potentially harmful compounds thus decreasing their toxicity.

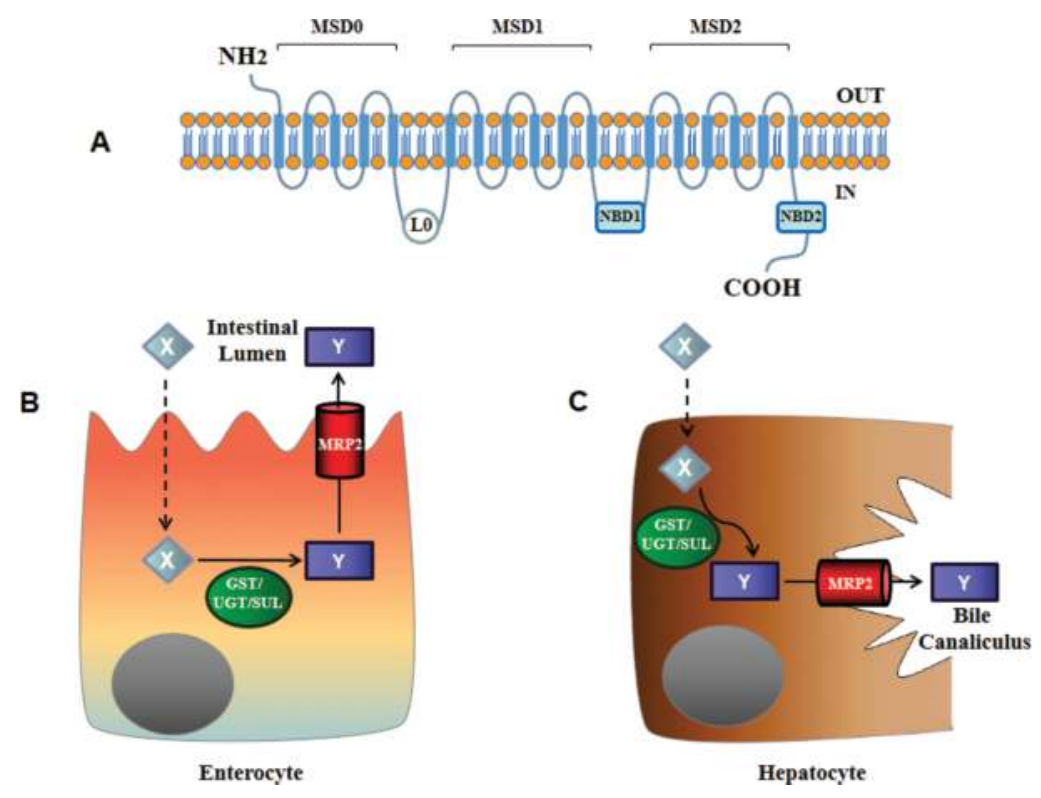

Figure 1. (A) Molecular structure of MRP2/ABCC2. MSDs: membrane-spanning domains; NBDs: nucleotide-binding domains; L0: linker segment 0 . (B) Coordinated action between phase II metabolizing enzymes and MRP2 in the enterocyte. Hydrophobic xenobiotics $(X)$ may enter the cell by diffusion through the apical membrane of the enterocyte. After that, they may suffer metabolic phase I reaction by cytochrome P450 and/or subsequent conjugation by phase II enzymes, such as UDP-glucuronosyltransferase (UGT) localized in the endoplasmic reticulum or glutathione S-transferase (GST) or sulfotransferase (SUL) localized in the cytosol. In the phase III, the more hydrophilic metabolites (Y) may be actively secreted into the intestinal lumen by MRP2. (C) Coordinated action between phase II metabolizing enzymes and MRP2 in the hepatocyte. Here, hydrophobic xenobiotics $(X)$ enter the cell through the basolateral pole of the membrane in the hepatocyte. After conjugation by phase II metabolizing enzymes, the final product (Y) may be secreted into bile by MRP2.

Selected substrates of MRP2 are included in Table 1. Studies using Groningen Yellow (GY)/ TR- Wistar [15, 16] or Eisai hyperbilirubinemic rats (EHBR) [17] that are rMrp2 deficient as a result of mutations leading to premature stop codons have helped to identify transporter 
substrates initially. Interestingly, ingredients of our daily diet are substrates for MRP2. That is the case of the tea component epicatechin, the dietary supplement chrysin [18, 19], and the meat-derived dietary carcinogen 2-amino-1-methyl-6-phenylimidazo[4,5-b]pyridine (PhIP) [20]. Finally, it is important to emphasize that there are MRP2 substrates which influence transporter expression thus influencing its own bioavailability. That is the case, for example, of tamoxifen [21].

\begin{tabular}{ll}
\hline Endogenous compounds & Exogenous compounds \\
\hline Glutathione & Anticancer drugs: doxorubicin, epirubicin, etoposide, irinotecan, methotrexate, \\
Bilirubin glucuronides & mitoxantrone, cisplatin, tamoxifen, vincristine, vinblastine, camptothecin \\
Conjugated bile salts & Antibiotics: ampicillin, azithromycin, cefodizime, ceftriaxone, grepafloxacine, \\
Leukotrienes C4, D4, E4 & irinotecan \\
Steroids & HIV drugs: adenovir, cidofovir, indinavir, lopinavir, nelfinavir, ritonavir, \\
(17ß-glucuronosyl estradiol) & saquinavir \\
Triiodo-L-thyronine & Other drugs:genistein-7-glucoside, p-aminohippurate, olmesartan, phloridzin, \\
ethinylestradiol-3-O-glucuronide & pravastatine, quercetin 4'- $\beta$-glucoside, temocaprilate, conjugates of \\
& acetaminophen, indomethacin, phenobarbital, sulfinpyrazone. \\
& Toxicants: S-glutathionyl-2,4-dinitrobenzene, S-glutathionyl ethacrynic acid, \\
& ochratoxin A, 2-amino-1-methyl-6-phenylimidazol[4,5-b]pyridin, 4- \\
& (methylnitrosamino)-1-(3-pyridyl)-1-buta-nol, $\alpha$-naphtylisothio-cyanate, \\
& heavy metal complexes (arsenic glutathione, Sb, Zn, Cu, Mn, Cd) \\
& Dyes: fluo-3, carboxydichloro fluorescein, sulfobromophthalein \\
& Flavonoids: epicatechin, chrysin \\
\hline
\end{tabular}

Table 1. Selected MRP2 substrates.

\section{Regulation of expression and activity of MRP2 by xenobiotics}

Expression of MRP2 can be regulated at different levels [22], which can be grouped in two main categories: (i) transcriptional level, implying changes in mRNA synthesis rate, or (ii) posttranscriptional level, comprising complex processes involving or not changes in MRP2 mRNA levels. Regarding the transcriptional regulation, the MRP2 promoter contains a number of binding sites recognizing a variety of transcription factors, which in turn can be activated by either endo- or xenobiotics [23, 24]. Thus, a wide variety of drugs, environmental pollutants, and natural toxins behave as ligands of transcription factors/nuclear receptors such as farnesoid $\mathrm{X}$-activated receptor (FXR), pregnane $\mathrm{X}$ receptor (PXR), liver $\mathrm{X}$ receptor $\alpha$ (LXR $\alpha$ ), and constitutive androstane receptor (CAR), to ultimately induce the synthesis of MRP2 mRNA [25]. They modulate MRP2 transcriptionally through binding to the response element 
ER-8, which extends from -401 to -376 bp of the MRP2 promoter [25]. Additionally, the study of MRP2 promoter identified binding sites for other transcription factors such as the nuclear factor-erythroid 2-related factor-2 (Nrf2), the peroxisome proliferator-activated receptor alpha (PPAR $\alpha)$, CCAAT/enhancer-binding protein- $\beta$ (C/EBP $\beta)$, and hepatic nuclear factors (HNFs), which can also influence the MRP2 expression at the transcriptional level. Finally, a particular transcriptional regulation involves the intracellular nucleotide cyclic adenosine monophosphate (cAMP) pathway, likely triggered by xenobiotics acting predominantly through binding to plasma membrane receptors. This was so far demonstrated in the intestine [26], where the treatment of Caco-2 human intestinal cells with the membrane-permeable analogue dibutyryl cAMP or the adenylyl cyclase activator forskolin led to a significant induction in hMRP2 protein and mRNA expression. Reporter gene and chromatin immunoprecipitation assays performed in this same study showed an increased binding of the transcription factors c-JUN and activating transcription factor-2 (ATF2) to a regulatory region containing activator protein-1 (AP-1) and cAMP response element (CRE) binding sites within the MRP2 promoter.

On the other hand, post-transcriptional MRP2 regulation can involve the dynamic endocytic retrieval and exocytic insertion of this transporter between the canalicular membrane and an intracellular pool of vesicles [27]. A variety of signal transduction pathways involving the activation of the mitogen-activated protein kinases (MAPK) A and C take part in these events [27-29]. Also, mRNA splicing may account for post-transcriptional regulation. As an example, alternative splicing of hMRP2 mRNA has been shown to be a cause underlying Dubin-Johnson syndrome as a consequence of synthesis of nonfunctional protein [30, 31]. Additionally, MRP2 can be translationally modulated. In this regard, Jones et al. [32] observed that under certain situations rMrp2 protein in rats is modified without changes in mRNA levels. This is not just attributed to a modified rate of protein degradation but to the presence of several rMrp2 transcription initiation sites in the 5 ' untranslated region $[7,33]$. The alternative use of these sites leads to the production of different rMrp2 mRNAs with differential translational efficiency.

What follows is a description of the regulatory properties of MRP2 as an important component of the ABC family in liver and intestine. The effects of xenobiotics on MRP2 expression and activity were particularly considered. Transcriptional and post-transcriptional regulations were described separately.

\subsection{Transcriptional regulation}

Several xenobiotics including therapeutic drugs, environmental pollutants, and natural toxins have shown to activate different transcription factors and nuclear receptors thus exhibiting the potential of increasing MRP2 expression [34]. However, not all xenobiotics induce the expression of MRP2. Indomethacin, a nonsteroidal anti-inflammatory drug, reduced the expression of rat rMrp2 at the mRNA and protein levels in the liver [35]. This reduction was associated with a diminished mRNA expression of the hepatic nuclear receptors CAR, FXR, PXR, retinoic acid receptor $\alpha(\operatorname{RAR} \alpha)$, and retinoid $\mathrm{X}$ receptor $\alpha(\mathrm{RXR} \alpha)$. This down-regulation of nuclear receptors is consistent with observations in endotoxin-treated rats that also proved to cause rMrp2 down-regulation at the transcriptional level [36, 37]. Intestinal injury caused 
by indomethacin can increase endotoxin levels in portal blood [38], which in turn induces several immune responses and oxidative stress, as shown by the reduced levels of hepatic GSH and increased levels of nitric oxide (NO) and nitrosothiols in portal blood [35]. In this regard, El Kasmi et al. demonstrated that dextran sulfate sodium-induced intestinal injury also downregulates hepatic mMrp2 expression in mice liver and that the intestinal microbiota and TLR4 (Toll-like receptor 4) are involved in this effect [39]. In addition, it was shown that mice with intestinal injury that received soy oil-based parenteral nutrition containing phytosterols exhibited an exacerbated decrease in mMrp2 mRNA levels. The phytosterol stigmasterol was at least partially involved and associated with increased levels of interleukin 6 (IL-6) mRNA and reduced levels of FXR mRNA in liver [39].

In contrast to indomethacin, several drugs are able to induce the expression of MRP2. For example, spironolactone (SL), a drug used to treat patients with edema and ascites, has been shown to increase bile flow in rats due to the up-regulation of rMrp2 at the transcriptional level, probably in response to increased PXR levels [40]. This up-regulation in rMrp2 resulted in increased efflux activity of the model substrate of rMrp2 dinitrophenyl-S-glutathione (DNP$\mathrm{SG})$ in vitro. These findings were in accordance with observations in patients exhibiting increased clearance of drugs co-administered with SL [41, 42]. Benznidazole (BZL), a nitroimidazole administered for treatment of Chagas disease, was also shown to induce rMrp2 protein expression [43] in rats. This induction is presumably mediated by PXR, since knockdown of the nuclear receptor in the hepatic cell line HepG2 prevented the induction of hMRP2 by this drug [44]. The antituberculosis agents rifampicin and isoniazid that cause liver injury also up-regulate hepatic rMrp2 protein expression in rats [45]. Interestingly, monoammonium glycyrrhizin, commonly present in Chinese herbal formulas used for hepatic protection, prevented such increases in rMrp2 expression. In addition rifampicin and isoniazid increased lipid peroxidation and GSH levels in hepatic tissue, indicating the presence of oxidative stress, which was also prevented by monoammonium glycyrrhizin.

Acetaminophen (APAP) represents one of the most common over-the-counter drugs, used as an effective and safe analgesic and antipyretic. Nevertheless, APAP overdose is very frequent and associated with severe liver injury. Although the mechanism underlying APAP toxicity is not completely understood, the CYP-biotransformation product $\mathrm{N}$-acetyl-p-benzoquinone imine (NAPQI) was described as a mediator of APAP toxic effects since it promotes GSH depletion and binds itself to cellular proteins [46]. APAP phase II metabolites resulting from conjugation with glucuronic acid and sulfate are known MRP2 substrates. Similarly, MRP2 transports the GSH conjugate of NAPQI, thus contributing to reduce the toxic burden exerted by APAP. In this regard, the administration of a single hepatotoxic dose of APAP to Wistar rats resulted in an increase in rMrp2 expression in liver plasma membranes [47]. In a similar study, an induction hepatic mMrp2 following Nrf2 activation was demonstrated in mice, clearly suggesting the presence of an adaptive mechanism to the APAP-triggered injury [48, 49]. In line with these observations, therapeutic activation of Nrf2 has been proposed as a possible strategy to ameliorate APAP-associated hepatotoxicity [50-52]. Nrf2 bears a special toxicological relevance due to its activation by pro-oxidant compounds and reactive metabolites usually associated with situations of drug overdose or exposure to environmental toxicants. Under 
homeostatic conditions, Nrf2 is sequestered in the cytosol by the Kelch-like ECH-associated protein 1 (Keap1) which promotes Nrf2 ubiquitination and proteosomal degradation. Upon an oxidative stimulus, it takes place a modification in the oxidation status of particular cysteine residues in the Keap1 molecule leading to Nrf2 dissociation and migration to the nucleus where it binds to antioxidant response elements (ARE) within the promoters and activates the transcription of target genes [53] including antioxidant and GSH synthesis enzymes and also drug transporters like MRP2 [54]. Management of Nrf2 activation could be applied to other cases of oxidative stress-associated hepatic injury. For instance, the Nrf2 activator N-acetylcysteine was described to ameliorate the rMrp2 down-regulation exerted by the pro-oxidant phytochemical timosaponin A3 [55]. Similarly, other Nrf2 activators are being tested in clinical trials for the treatment of hepatic and extrahepatic diseases [53].

Environmental pollutants such as arsenite significantly increased rMrp2 protein expression in rat liver after 2 weeks of exposure. Longer exposure treatment (4 or 6 weeks) also increased rMrp2 expression but to a lesser extent [56]. Arsenite not only regulates Mrp2 but is also an MRP2 substrate, so transporter induction may help to counteract the toxic effects of arsenite in the liver. In agreement with this, arsenite content in bile decreased with the exposure time in the same manner as rMrp2 protein induction. Lipid peroxidation was increased and GSH peroxidase activity was reduced in the liver at 4 and 6 weeks of arsenite exposure, indicating a probable effect of oxidative stress in attenuating hepatic rMrp2 induction. This regulation of Mrp2 may explain the dual effects reported for arsenite exposure [57].

The T-2 mycotoxin is commonly found in different crops. Prolonged exposure (3 weeks) of poultry to T-2 reduced cMrp2 mRNA expression in the liver of broiler chickens [58]. Although the authors suggest that PXR may be involved in the down-regulation observed, no studies were conducted to prove that. The organochlorine pesticides 2,4'-dichlorodiphenyltrichloroethane (DDT), 4,4'-DDT, chlordane, heptachlor, dieldrin, and lindane, highly resistant to degradation, were shown to increase hMRP2 mRNA in HepaRG cells after a 48-h exposure [59]. This regulation could be mediated by PXR, since this nuclear receptor expression was increased in human hepatocytes after treatment with chlordane, dieldrin, and endosulfan [60].

Bisphenol A (BPA) is a typical contaminant of food, water, and air. A study evaluating the association between the expression of drug transporters in fetal liver and BPA exposure showed a positive correlation between BPA levels and hMRP2 expression. A similar correlation was described between BPA levels and Nrf2 expression, suggesting also a mediation of this transcription factor in the hMRP2 regulation by BPA and agreeing well with a previous report showing Nrf2 activation by BPA in vitro [61, 62].

Transcriptional regulation of MRP2 by xenobiotics was also demonstrated in extrahepatic tissues like the small intestine. An example of therapeutic drugs affecting MRP2 gene expression is rifampicin, a well-known PXR agonist which has been demonstrated to increase hMRP2 expression and activity in healthy volunteers. Fromm et al. reported an up-regulation of hMRP2 mRNA and protein in duodenal biopsies [63]. Later, Oswald et al. showed the impact of this regulation on oral availability and efficacy of the coadministered drug ezetimibe [64]. The same inducing effect was reported using the human-derived cell line LS180 [65]. Similarly, carbamazepine is another PXR agonist [66] shown to increase hMRP2 mRNA and protein levels 
in human healthy volunteers and also to reduce intestinal absorption of the co-administered MRP2 substrate talinolol [67].

Even though there are only few reports on drug-drug interactions associated with PXRdependent modulation of intestinal MRP2, many other agents have been shown to regulate its expression via PXR. Pregnenolone-16 $\alpha$-carbonitrile, a synthetic steroid, induced mMrp2 mRNA expression in jejunum of C57BL/6 mice ( $200 \mathrm{mg} / \mathrm{kg}$, i.p., 4 days). A concomitant upregulation of PXR mRNA was observed and the involvement of this nuclear receptor was confirmed using PXR knockout mice [68]. The antiviral agents and PXR agonists efavirenz and saquinavir [69] also up-regulated hMRP2 expression in LS180 cells [65, 70]. Since these drugs are usually involved in long-term treatments, coadministration with MRP2 substrates could result in unwanted drug-drug interactions. In the same human intestinal cell line, the effect of the endothelin receptor antagonist bosentan [71] and the antineoplastic mitotane [72] was demonstrated. They both exerted a significant hMRP2 induction concomitantly with PXR activation at pharmacologically relevant concentrations.

In some studies, the increases in MRP2 expression were correlated experimentally with increased transport activity. Examples of these drugs are BZL and SL, both PXR agonists. Perdomo et al. reported an induction of rMrp2 protein in jejunum of BZL-treated rats $(100 \mathrm{mg} /$ $\mathrm{kg}$, i.p., 3 days) [43]. This change was accompanied with an increased efflux of DNP-SG to the intestinal lumen. These results not only demonstrate higher secretion of rMrp2 substrates but also strongly suggest a restriction in the absorption of xenobiotics incorporated luminally in BZL-treated rats. Similarly, SL was demonstrated to increase serosal to mucosal transport of DNP-SG well correlating with increased rMrp2 mRNA and protein expression in rat proximal jejunum. The PXR antagonist ketoconazole was able to prevent this induction, suggesting mediation by this nuclear receptor [73].

Cimetidine and quinidine have been shown to increase both hMRP2 and PXR expressions in T84 cells [74]. Similarly, the anticonvulsant phenobarbital induced PXR mRNA and hMRP2 mRNA and protein at the same time in Caco-2 cells [75]. On the contrary, MRP2 expression is down-regulated by drugs that decrease PXR expression. Haslam et al. reported such an effect in T84 cells for the cholesterol-lowering drug atorvastatin and the anticancer agents topotecan and irinotecan [74].

Xenobiotics can regulate expression of intestinal MRP2 interacting with nuclear receptors other than PXR. That is the case of the bcl-2 inhibitor obatoclax, which at nanomolar concentrations induced hMRP2 mRNA in LS180 cells through activation of the aryl hydrocarbon receptor [76]. Another example is the proteasome inhibitor bortezomib, which also increases hMRP2 mRNA expression in SW-480 human cells [77]. Even though the mediator has still to be identified, the transcription factor Nrf2 appears to be the main candidate considering its simultaneous upregulation and also the well-demonstrated relationship between MRP2 induction and Nrf2 activation in tissues like liver [49], kidney [78], and brain [79].

Among the natural compounds modulating intestinal MRP2, the isothiocyanates sulforaphane (SF) and erucin (ER) were well studied. Derived from cruciferous vegetables, they have drawn the attention of the researchers due to their anticancer properties [80]. After microarray studies, 
Traka et al. reported hMRP2 up-regulation in Caco-2 cells treated with SF (50 $\mu \mathrm{M}, 24 \mathrm{~h})$ [81]. They confirmed this finding by RT-PCR analysis. Using the same model, Jakubíková et al. showed a similar hMRP2 mRNA increase after treatment with SF and with ER $(20 \mu \mathrm{M}, 24 \mathrm{~h})$ [82]. This effect appears to be partly mediated by phosphoinositide 3-kinase (PI3K)/AKT, considering the inhibition exhibited by the PI3K/AKT inhibitor LY294002. Later, in analogous experimental conditions, Harris and Jeffery demonstrated an induction also at protein level [83]. Considering that $\mathrm{Nrf} 2$ is activated by SF [84], this transcription factor may play a role in MRP2 up-regulation.

Other naturally occurring xenobiotics found to modulate intestinal MRP2 are the polyphenols quercetin and resveratrol (RES). The first one was demonstrated to up-regulate hMRP2 at protein level in Caco-2 cells (50 and $100 \mu \mathrm{M}, 72 \mathrm{~h}$ ). A coordinated induction of the phase II enzyme UGT1A6 was also observed, suggesting reduced absorption and enhanced secretion of glucuronides at intestinal level [85]. Studies using RES have become of strong interest after the increasing evidence regarding its beneficial health effects. A short time ago, RES ability to down-regulate MRP2 at mRNA and protein levels has been proven in rat intestine and Caco-2 cells [86]. The functional impact was evaluated in the latter model by determination of intracellular retention of the MRP2 substrate methotrexate (MTX). Treatment with RES increased the accumulation of MTX, suggesting a suppressed efflux activity. Moreover, in an attempt to clarify the mechanism, the authors found a concomitant inhibition of the insulinlike growth factor receptor 1 (IGF-1R)/AKT/ERK signaling pathway.

\subsection{Post-transcriptional regulation}

As anticipated, post-transcriptional regulation of MRP2 activity may also occur in response to exposition to xenobiotics. Faldaprevir is a drug used to treat patients with hepatitis $C$ in spite that it causes hyperbilirubinemia. Acute treatment of human and rat hepatocytes with faldaprevir inhibited hMRP2-/rMrp2-mediated efflux of bilirubin glucuronides into bile [87]. This may partially explain the impaired bilirubin disposition by faldaprevir. However, toxicology studies in monkeys and patients showed that the bilirubin accumulated during faldaprevir treatment was mainly unconjugated, suggesting that the main cause is probably inhibition of glucuronidation ather than excretion of the conjugated metabolites. Simeprevir, another drug used to treat hepatitis, causes hyperbilirubinemia composed by conjugated and unconjugated bilirubin, which supports an impaired hMRP2 efflux activity [88].

Ethynylestradiol (EE) and genistein (GNT) are estrogenic compounds of particular relevance considering their oral incorporation as components of contraceptives formulations and soyderived food, respectively. Interestingly, they were demonstrated to regulate intestinal MRP2 at post-transcriptional level, although showing a noticeable dose and model dependence. Thus, it was initially found that EE at a cholestatic dose $(5 \mathrm{mg} / \mathrm{kg} \mathrm{b.w}$. day, for 5 consecutive days, s.c.) down-regulates rMrp2 expression and function in rat proximal jejunum, without changes in mRNA levels [89]. However, at pharmacological concentrations (0.5-5 pM) EE upregulates hMRP2 expression and activity in Caco- 2 cells. This hMRP2 induction was estrogen receptor $\beta(E R \beta)$-mediated but not associated with changes at the mRNA level, thus suggesting a post-transcriptional regulation [90]. The implication of ER $\beta$ in such kind of regulation is 
possible since it was reported to regulate miRNAs expression [91] which, in turn, can alter hMRP2 expression [92]. Similarly, Caco-2 cells exposed to GNT $(1 \mu \mathrm{M}, 48 \mathrm{~h})$ exhibited an ER $\beta$-mediated hMRP2 induction at protein level without changes in expression at the mRNA level. This was associated with increased transporter activity and enhanced protection against 1-chloro-2,4-dinitrobenzene, an MRP2 substrate precursor [90]. GNT can also modulate MRP2 activity in an acute fashion, i.e., without changes in transporter expression. Some years ago, it was reported that this isoflavone competitively inhibits hepatic rMrp2 in isolated and perfused rat liver model [93]. In line with this result, Yokooji et al. demonstrated that GNT administered intravenously reduced rMrp2-mediated secretion of irinotecan hydrochloride and its metabolites in rat liver and intestine [94].

The uricosuric drug probenecid represents another example of xenobiotics affecting intestinal MRP2 activity without modifying MRP2 expression. Probenecid is a classical competitive inhibitor of organic anions transport also used in the clinical practice to enhance plasma levels of antibiotics. Although nonspecific, its inhibitory effect on intestinal MRP2 was clearly demonstrated in rats [95] and in Caco-2 cells [90]. Nowadays, more potent and specific MRP inhibitors like MK571 are preferred for characterization of transport specificity. Finally, various members of the large family of nonsteroidal anti-inflammatory drugs are recognized MRP2 modulators [96]. In intestine, indomethacin was shown to inhibit MRP2 and to increase sulfasalazine transepithelial permeability, both in rat small intestine and in Caco-2 cell monolayers [97]. In agreement with these findings, Caco-2 cells coincubated with indomethacin exhibited an increased permeability to the hMRP2 substrates fluvastatin [98] and colchicine [99].

\section{Conclusion}

Although the organisms are permanently exposed to a wide range of xenobiotics such as therapeutic drugs, environmental pollutants, and natural toxins, they possess a sophisticate system of detoxification in which metabolizing enzymes and transport proteins play an essential role. Evidence from in vitro and in vivo studies unambiguously demonstrates that MRP2 is a crucial actor in protecting specific tissues from xenobiotic toxicity. It is noteworthy that MRP2 also plays a crucial role in elimination of endogenous metabolites. A list of relevant and well-recognized substrates of MRP2 is presented in Table 1. Two relevant tissues expressing MRP2 are the liver and the small intestine. It should be noted that other participants not contemplated in this review, such as a bunch of metabolizing enzymes as well as members of the family of $\mathrm{ABC}$ transporters different from MRP2, are additionally involved in xenobiotic detoxification.

Expression and activity of MRP2 can be modulated at both transcriptional and post-transcriptional levels. The nuclear receptor PXR plays a major role in transcriptional regulations. PXR functions as sensor for many agents and its activation leads to a coordinated response on biotransformation enzymes and transport systems. Examples of these agents are rifampicin, carbamazepine, pregnenolone-16 $\alpha$-carbonitrile, efavirenz, saquinavir, BZL, SL, etc. Other 
xenobiotics such as bortezomib, BPA, and sulforaphane regulate MRP2 as a result of the interaction with Nrf2. Alternatively, regulation of MRP2 activity by xenobiotics can occur without changes in transporter expression, as it was demonstrated to GNT. Finally, it is important to note that regulation of MRP2 activity by therapeutic agents can result in changes in their therapeutic efficacy or safety, or alternative in drug-drug interactions if other drugs, substrates of MRP2, are simultaneously administered.

Abbreviations: ABC, ATP-binding cassette; AP-1, activator protein-1; APAP, acetaminophen; ARE, antioxidant response elements; ATF2, activating transcription factor-2; BPA, bisphenol A; BZL, benznidazole; C/EBP $\beta$, CCAAT/enhancer-binding protein- $\beta$; $\mathrm{CAMP}$, cyclic adenosine monophosphate; $\mathrm{CAR}$, constitutive androstane receptor; $\mathrm{CRE}$, cAMP response element; $\mathrm{CYP}$, cytochrome P450; DDT, dichlorodiphenyltrichloroethane; DNP-SG, dinitrophenyl-S-glutathione; EE, ethynylestradiol; EHBR, Eisai hyperbilirubinemic rats; ER, erucin; ER $\beta$, estrogen receptor $\beta$; FXR, farnesoid X-activated receptor; GNT, genistein; GY, Groningen Yellow; GSH, glutathione; GST, glutathione S-transferase; HNFs, hepatic nuclear factors; IGF-1R, insulinlike growth factor receptor 1; IL-6, interleukin 6; Keap1, Kelch-like ECH-associated protein 1; L0, linker segment 0 ; LXR $\alpha$, liver X receptor $\alpha$; MAPK, mitogen-activated protein kinases; MRP, multidrug resistance-associated protein; MRP2, multidrug resistance-associated protein 2; hMRP2, human MRP2; rMrp2, rat Mrp2; mMrp2, mouse Mrp2; cMrp2, chickenMrp2; MSDs, membrane-spanning domains; MTX, methotrexate; NAPQI, N-acetyl-p-benzoquinone imine; NBDs, nucleotide-binding domains; NO, nitric oxide; Nrf2, nuclear factor-erythroid 2- related factor-2; PhIP, 2-amino-1-methyl-6-phenylimidazo[4,5-b]pyridine; PI3K, phosphoinositide 3kinase; PPAR $\alpha$, peroxisome proliferator activated receptor alpha; PXR, pregnane $\mathrm{X}$ receptor; $\operatorname{RAR} \alpha$, retinoic acid receptor $\alpha$; RES, resveratrol; RXR $\alpha$, retinoid X receptor $\alpha$; SF, sulforaphane; SL, spironolactone; SULT, sulphotransferase; TLR4, tool-like receptor 4; UGT, UDP-glucuronosyltransferase.

\section{Author details}

Maite R. Arana ${ }^{1}$, Guillermo N. Tocchetti ${ }^{1}$, Juan P. Rigalli ${ }^{1,2}$, Aldo D. Mottino ${ }^{1}$, Fabiana García ${ }^{3}$ and Silvina S.M. Villanueva ${ }^{{ }^{*}}$

*Address all correspondence to: villanueva@ifise-conicet.gov.ar

1 Instituto de Fisiología Experimental (IFISE-CONICET)-Facultad de Ciencias Bioquímicas y Farmacéuticas-Universidad Nacional de Rosario, Rosario, Santa Fe, Argentina

2 Department of Clinical Pharmacology and Pharmacoepidemiology, Heidelberg University, Heidelberg, Germany

3 Facultad de Ciencias Médicas-Universidad Nacional de Rosario-CONICET-Cátedra Fisiología Humana, Rosario, Santa Fe, Argentina 


\section{References}

[1] Suzuki H, Sugiyama Y. Role of metabolic enzymes and efflux transporters in the absorption of drugs from the small intestine. Eur J Pharm Sci 2000;12:3-12. doi:10.1016/ S0928-0987(00)00178-0.

[2] Liu L, Pang KS. The roles of transporters and enzymes in hepatic drug processing. Drug Metab Dispos 2005;33:1-9. doi:10.1124/dmd.104.001149.

[3] Dietrich CG, Geier a, Oude Elferink RPJ. ABC of oral bioavailability: transporters as gatekeepers in the gut. Gut 2003;52:1788-95. doi:10.1136/gut.52.12.1788.

[4] Jedlitschky G, Hoffmann U, Kroemer H. Structure and function of the MRP2 (ABCC2) protein and its role in drug disposition. Expert Opin Drug Metab Toxicol 2006;2:35166.

[5] Payen L, Sparfel L, Courtois A, Vernhet L, Guillouzo A, Fardel O. The drug efflux pump MRP2: regulation of expression in physiopathological situations and by endogenous and exogenous compounds. Cell Biol Toxicol 2002;18:221-33. doi:10.1023/A: 1016020626941.

[6] Fardel O, Jigorel E, Le Vee M, Payen L. Physiological, pharmacological and clinical features of the multidrug resistance protein 2. Biomed Pharmacother 2005;59:104-14. doi:10.1016/j.biopha.2005.01.005.

[7] Zhang Y, Li W, Vore M. Translational regulation of rat multidrug resistance- associated protein 2 expression is mediated by upstream open reading frames in the $5 \mathrm{~J}$ untranslated region. Mol Pharmacol 2007;71:377-83. doi:10.1124/mol.106.029793.2002.

[8] Mottino AD, Hoffman T, Jennes L, Vore M. Expression and localization of multidrug resistant protein mrp2 in rat small intestine. J Pharmacol Exp Ther 2000;293:717-23.

[9] Clifton G, Kaplowitz N. The glutathione S-transferases of the small intestine in the rat. Cancer Res 1977;37:788-91.

[10] Shelby MK, Cherrington NJ, Vansell NR, Klaassen CD. Tissue mRNA expression of the rat UDP-glucuronosyltransferase gene family. Drug Metab Dispos 2003;31:326-33. doi: 10.1124/dmd.31.3.326.

[11] Keppler D, Leier I, Jedlitschky G. Transport of glutathione conjugates and glucuronides by the multidrug resistance proteins MRP1 and MRP2. Biol Chem 1997;378:787-91.

[12] Keppler D, König J. Hepatic secretion of conjugated drugs and endogenous substances. Semin Liver Dis 2000;20:265-72. doi:10.1055/s-2000-9391.

[13] Paulusma C, Kothe M, Bakker C, Bosma P, van Bokhoven I, van Marle J, et al. Zonal down-regulation and redistribution of the multidrug resistance protein 2 during bile duct ligation in rat liver. Hepatology 2000;31:684-93. 
[14] Chowdhury JR, Novikoff PM, Chowdhury NR, Novikoff AB. Distribution of UDPglucuronosyltransferase in rat tissue. Proc Natl Acad Sci U S A 1985;82:2990-4.

[15] Jansen PL, Peters WH, Lamers WH. Hereditary chronic conjugated hyperbilirubinemia in mutant rats caused by defective hepatic anion transport. Hepatology 1985;5:573-9. doi:10.1002/hep.1840050408.

[16] Huber M, Guhlmann A, Jansen P, Keppler D. Hereditary defect of hepatobiliary cysteinyl leukotriene elimination in mutant rats with defective hepatic anion excretion. Hepatology 1987;7:224-8.

[17] Takenaka O, Horie T, Kobayashi K, Suzuki H, Sugiyama Y. Kinetic analysis of hepatobiliary transport for conjugated metabolites in the perfused liver of mutant rats (EHBR) with hereditary conjugated hyperbilirubinemia. Pharm Res 1995;12:1746-55.

[18] Vaidyanathan JB, Walle T. Transport and metabolism of the tea flavonoid (-)-epicatechin by the human intestinal cell line Caco-2. Pharm Res 2001;18:1420-5. doi:10.1023/A: 1012200805593.

[19] Walle UK, Galijatovic A, Walle T. Transport of the flavonoid chrysin and its conjugated metabolites by the human intestinal cell line Caco-2. Biochem Pharmacol 1999;58:4318. doi:10.1016/S0006-2952(99)00133-1.

[20] Dietrich CG, De Waart DR, Ottenhoff R, Bootsma AH, van Gennip AH, Elferink RP. Mrp2-deficiency in the rat impairs biliary and intestinal excretion and influences metabolism and disposition of the food-derived carcinogen 2-amino-1-methyl-6phenylimidazo. Carcinogenesis 2001;22:805-11. doi:10.1093/carcin/22.5.805.

[21] Kauffmann HM, Keppler D, Gant TW, Schrenk D. Induction of hepatic mrp2 (cmrp/ cmoat) gene expression in nonhuman primates treated with rifampicin or tamoxifen. Arch Toxicol 1998;72:763-8. doi:10.1007/s002040050571.

[22] Gerk PM, Vore M. Regulation of expression of the multidrug resistance- associated protein 2 (MRP2) and its role in drug disposition. J Pharmacol Exp Ther 2002;302:40715. doi:10.1124/jpet.102.035014.chemotherapeutic.

[23] Kauffmann HM, Schrenk D. Sequence analysis and functional characterization of the 5 '-flanking region of the rat multidrug resistance protein 2 (mrp2) gene. Biochem Biophys Res Commun 1998;245:325-31. doi:10.1006/bbrc.1998.8340.

[24] Stöckel B, König J, Nies a T, Cui Y, Brom M, Keppler D. Characterization of the 5'flanking region of the human multidrug resistance protein 2 (MRP2) gene and its regulation in comparison with the multidrug resistance protein 3 (MRP3) gene. Eur J Biochem 2000;267:1347-58.

[25] Kast HR, Goodwin B, Tarr PT, Jones SA, Anisfeld AM, Stoltz CM, et al. Regulation of multidrug resistance-associated protein 2 (ABCC2) by the nuclear receptors pregnane $\mathrm{X}$ receptor, farnesoid $\mathrm{X}$-activated receptor, and constitutive androstane receptor. J Biol Chem 2002;277:2908-15. doi:10.1074/jbc.M109326200. 
[26] Arana MR, Tocchetti GN, Domizi P, Arias A, Rigalli JP, Ruiz ML, et al. Coordinated induction of GST and MRP2 by cAMP in Caco-2 cells: role of protein kinase A signaling pathway and toxicological relevance. Toxicol Appl Pharmacol 2015;287:178-90. doi: 10.1016/j.taap.2015.06.003.

[27] Häussinger D, Schmitt M, Weiergraber O, Kubitz R. Short-term regulation of canalicular transport. Semin Liver Dis 2000;20:307-21.

[28] Mottino AD, Cao J, Veggi LM, Crocenzi F, Roma MG, Vore M. Altered localization and activity of canalicular Mrp2 in estradiol-17B-D-glucuronide-induced cholestasis. Hepatology 2002;35:1409-19. doi:10.1053/jhep.2002.33327.

[29] Roelofsen H, Soroka CJ, Keppler D, Boyer JL. Cyclic AMP stimulates sorting of the canalicular organic anion transporter (Mrp2/cMoat) to the apical domain in hepatocyte couplets. J Cell Sci 1998;111:1137-45.

[30] Paulusma CC, Kool M, Bosma PJ, Scheffer GL, Borg F Ter, Scheper RJ, et al. A mutation in the human canalicular multispecific organic anion transporter gene causes the Dubin-Johnson syndrome. Hepatology 1997;25:1539-42. doi:10.1002/hep.510250635.

[31] Mor-Cohen R, Zivelin a, Rosenberg N, Goldberg I, Seligsohn U. A novel ancestral splicing mutation in the multidrug resistance protein 2 gene causes Dubin-Johnson syndrome in Ashkenazi Jewish patients. Hepatol Res 2005;31:104-11. doi:S1386-6346(04)00330-4 [pii] \r10.1016/j.hepres.2004.11.010.

[32] Jones BR, Li W, Cao J, Hoffman TA, Gerk PM, Vore M. The role of protein synthesis and degradation in the post-transcriptional regulation of rat multidrug resistance- associated protein 2 (Mrp2, Abcc2). Mol Pharmacol 2005;68:701-10. doi:10.1124/mol. 105.013144.independent.

[33] Zhang Y, Zhao T, Li W, Vore M. The 5'-untranslated region of multidrug resistance associated protein 2 (MRP2; ABCC2) regulates downstream open reading frame expression through translational regulation. Mol Pharmacol 2010;77:237-46. doi: 10.1124/mol.109.058982.

[34] di Masi A, Marinis E De, Ascenzi P, Marino M. Nuclear receptors CAR and PXR: molecular, functional, and biomedical aspects. Mol Aspects Med 2009;30:297-343. doi: 10.1016/j.mam.2009.04.002.

[35] Fujiyama N, Shitara Y, Horie T. The mechanism of the down-regulation of hepatic transporters in rats with indomethacin-induced intestinal injury. Dig Dis Sci 2013;58:1891-8. doi:10.1007/s10620-013-2587-z.

[36] Cherrington NJ, Slitt AL, Li N, Klaassen CD. Lipopolysaccharide-mediated regulation of hepatic transporter mRNA levels in rats. Drug Metab Dispos 2004;32:734-41. doi: 10.1124/dmd.32.7.734.

[37] Fang C, Yoon S, Tindberg N, Järveläinen HA, Lindros KO, Ingelman-Sundberg M. Hepatic expression of multiple acute phase proteins and down-regulation of nuclear 
receptors after acute endotoxin exposure. Biochem Pharmacol 2004;67:1389-97. doi: 10.1016/j.bcp.2003.12.012.

[38] Masubuchi Y, Masuda E, Horie T. Multiple mechanisms in indomethacin-induced impairment of hepatic cytochrome P450 enzymes in rats. Gastroenterology 2002;122:774-83. doi:10.1053/gast.2002.31886.

[39] El Kasmi K, Anderson A, Devereaux M, Vue P, Zhang W, Setchell K, et al. Phytosterols promote liver injury and Kupffer cell activation in parenteral nutrition-associated liver disease. Sci Transl Med 2013;5:206ra137. doi:10.1038/jid.2014.371.

[40] Ruiz ML, Villanueva SS, Luquita MG, Sánchez-Pozzi EJ, Crocenzi FA, Pellegrino JM, et al. Mechanisms involved in spironolactone-induced choleresis in the rat: role of multidrug resistance-associated protein 2. Biochem Pharmacol 2005;69:531-9. doi: 10.1016/j.bcp.2004.10.017.

[41] Miguet J, Vuitton D, Thebault-Lucas A, Joanne C, Dhumeaux D. Spironolactone and enzyme induction in patients with alcoholic cirrhosis. Gastroenterology 1980;78:9961000 .

[42] Wirth KE, Frölich JC, Holliffield JW, Falkner FC, Sweetman BS, Oates JA. Metabolism of digitoxin in man and its modification by spironolactone. Eur J Clin Pharmacol 1976;9:345-54.

[43] Perdomo VG, Rigalli JP, Villanueva SSM, Ruiz ML, Luquita MG, Echenique CG, et al. Modulation of biotransformation systems and $A B C$ transporters by benznidazole in rats. Antimicrob Agents Chemother 2013;57:4894-902. doi:10.1128/AAC.02531-12.

[44] Rigalli JP, Perdomo VG, Luquita MG, Villanueva SSM, Arias A, Theile D, et al. Regulation of biotransformation systems and abc transporters by benznidazole in HepG2 cells: involvement of pregnane X-receptor. PLoS Negl Trop Dis 2012;6. doi:10.1371/ journal.pntd.0001951.

[45] Zhou L, Song Y, Zhao J, Qin H, Zhang G, Zhou Y, et al. Monoammonium glycyrrhizinate protects rifampicin- and isoniazid-induced hepatotoxicity via regulating the expression of transporter Mrp2, Ntcp, and Oatp1a4 in liver. Pharm Biol 2016;54:931-7. doi: 10.3109/13880209.2015.1070878.

[46] McGill M, Jaeschke H. Recent advances in relation to hepatotoxicity and diagnosis. Pharm Res 2014;30:2174-87. doi:10.1007/s11095-013-1007-6.METABOLISM.

[47] Ghanem CI, Gómez PC, Arana MC, Perassolo M, Ruiz ML, Villanueva SSM, et al. Effect of acetaminophen on expression and activity of rat liver multidrug resistance-associated protein 2 and P-glycoprotein. Biochem Pharmacol 2004;68:791-8. doi:10.1016/ j.bcp.2004.05.014.

[48] Aleksunes LM, Scheffer GL, Jakowski AB, Pruimboom-Brees IM, Manautou JE. Coordinated expression of multidrug resistance-associated proteins (Mrps) in mouse 
liver during toxicant-induced injury. Toxicol Sci 2006;89:370-9. doi:10.1093/toxsci/ kfi332.

[49] Maher JM, Dieter MZ, Aleksunes LM, Slitt AL, Guo G, Tanaka Y, et al. Oxidative and electrophilic stress induces multidrug resistance-associated protein transporters via the nuclear factor-E2-related factor-2 transcriptional pathway. Hepatology 2007;46:1597610. doi:10.1002/hep.21831.

[50] Wang W, Guan C, Sun X, Zhao Z, Li J, Fu X, et al. Tanshinone IIA protects against acetaminophen-induced hepatotoxicity via activating the Nrf2 pathway. Phytomedicine 2016;23:589-96. doi:10.1016/j.phymed.2016.02.022.

[51] Jiang Y, Wang Y, Tan H, Yu T, Fan X, Chen P, et al. Schisandrol B protects against acetaminophen-induced acute hepatotoxicity in mice via activation of the NRF2/ARE signaling pathway. Acta Pharmacol Sin 2016;37:382-9. doi:10.1038/aps.2015.120.

[52] Noh JR, Kim YH, Hwang JH, Choi DH, Kim KS, Oh WK, et al. Sulforaphane protects against acetaminophen-induced hepatotoxicity. Food Chem Toxicol 2015;80:193-200. doi:10.1016/j.fct.2015.03.020.

[53] Battaille A, Manautou JE. Nrf2: a potential target for new therapeutics in liver disease. Clin Pharmacol Ther 2012;92:340-8. doi:10.1016/j.biotechadv.2011.08.021.Secreted.

[54] Vollrath V, Wielandt AM, Iruretagoyena M, Chianale J. Role of Nrf2 in the regulation of the Mrp2 (ABCC2) gene. Biochem J 2006;395:599-609. doi:10.1042/BJ20051518.

[55] Wu Z-T, Qi X-M, Sheng J-J, Ma L-L, Ni X, Ren J, et al. Timosaponin A3 induces hepatotoxicity in rats through inducing oxidative stress and down-regulating bile acid transporters. Acta Pharmacol Sin 2014;35:1188-98. doi:10.1038/aps.2014.65.

[56] Li G xing, Pei Q ling, Gao Y, Liu K ming, Nie J sheng, Han G, et al. Protective effects of hepatocellular canalicular conjugate export pump (Mrp2) on sodium arsenite-induced hepatic dysfunction in rats. Exp Toxicol Pathol 2007;58:447-53. doi:10.1016/j.etp. 2007.02.001.

[57] Liu B, Pan S, Dong X, Qiao H, Jiang H, Krissansen GW, et al. Opposing effects of arsenic trioxide on hepatocellular carcinomas in mice. Cancer Sci 2006;97:675-81. doi:10.1111/ j.1349-7006.2006.00230.x.

[58] Osselaere A, Li SJ, De Bock L, Devreese M, Goossens J, Vandenbroucke V, et al. Toxic effects of dietary exposure to T-2 toxin on intestinal and hepatic biotransformation enzymes and drug transporter systems in broiler chickens. Food Chem Toxicol 2013;55:150-5. doi:10.1016/j.fct.2012.12.055.

[59] Bucher S, Le Vee M, Jouan E, Fardel O. Regulation of hepatic drug transporter activity and expression by organochlorine pesticides. J Biochem Mol Toxicol 2014;28:119-28. doi:10.1002/jbt. 
[60] Coumoul X, Diry M, Barouki R. PXR-dependent induction of human CYP3A4 gene expression by organochlorine pesticides. Biochem Pharmacol 2002;64:1513-9. doi: 10.1016/S0006-2952(02)01298-4.

[61] Chepelev NL, Enikanolaiye MI, Chepelev LL, Almohaisen A, Chen Q, Scoggan KA, et al. Bisphenol A activates the Nrf1/2-antioxidant response element pathway in HEK 293 cells. Chem Res Toxicol 2013;26:498-506. doi:10.1021/tx400036v.

[62] Moscovitz JE, Nahar MS, Shalat SL, Slitt AL, Dolinoy DC, Aleksunes LM. Correlation between conjugated bisphenol A concentrations and efflux transporter expression in human fetal livers. Drug Metab Dispos 2016;44:1061-5. doi:10.1124/dmd.115.068668.

[63] Fromm MF, Kauffmann HM, Fritz P, Burk O, Kroemer HK, Warzok RW, et al. The effect of rifampin treatment on intestinal expression of human MRP transporters. Am J Pathol 2000;157:1575-80. doi:10.1016/S0002-9440(10)64794-3.

[64] Oswald S, Haenisch S, Fricke C, Sudhop T, Remmler C, Giessmann T, et al. Intestinal expression of P-glycoprotein (ABCB1), multidrug resistance associated protein 2 (ABCC2), and uridine diphosphate-glucuronosyltransferase 1A1 predicts the disposition and modulates the effects of the cholesterol absorption inhibitor ezetimibe in. Clin Pharmacol Ther 2006;79:206-17. doi:10.1016/j.clpt.2005.11.004.

[65] König SK, Herzog M, Theile D, Zembruski N, Haefeli WE, Weiss J. Impact of drug transporters on cellular resistance towards saquinavir and darunavir. J Antimicrob Chemother 2010;65:2319-28. doi:10.1093/jac/dkq324.

[66] Luo G, Cunningham M, Kim S, Burn T, Lin J, Sinz M, et al. CYP3A4 induction by drugs: correlation between a pregnane $\mathrm{X}$ receptor reporter gene assay and CYP3A4 expression in human hepatocytes. Drug Metab Dispos 2002;30:795-804. doi:10.1124/dmd.30.7.795.

[67] Giessmann T, May K, Modess C, Wegner D, Hecker U, Zschiesche M, et al. Carbamazepine regulates intestinal $\mathrm{P}$-glycoprotein and multidrug resistance protein MRP2 and influences disposition of talinolol in humans. Clin Pharmacol Ther 2004;76:192-200. doi:10.1016/j.clpt.2004.04.011.

[68] Cheng X, Klaassen CD. Regulation of mRNA expression of xenobiotic transporters by the pregnane $X$ receptor in mouse liver, kidney, and intestine. Drug Metab Dispos 2006;34:1863-7. doi:10.1124/dmd.106.010520.

[69] Sharma D, Lau AJ, Sherman MA, Chang TKH. Agonism of human pregnane X receptor by rilpivirine and etravirine: comparison with first generation non-nucleoside reverse transcriptase inhibitors. Biochem Pharmacol 2013;85:1700-11. doi:10.1016/j.bcp. 2013.04.002.

[70] Weiss J, Herzog M, König S, Storch CH, Ketabi-Kiyanvash N, Haefeli WE. Induction of multiple drug transporters by efavirenz. J Pharmacol Sci 2009;109:242-50. doi:10.1254/ jphs.08209FP. 
[71] Weiss J, Baumann S, Theile D, Haefeli WE. Desmethyl bosentan displays a similar in vitro interaction profile as bosentan. Pulm Pharmacol Ther 2015;30:80-6. doi:10.1016/ j.pupt.2014.12.001.

[72] Theile D, Haefeli WE, Weiss J. Effects of adrenolytic mitotane on drug elimination pathways assessed in vitro. Endocrine 2015;49:842-53. doi:10.1007/s12020-014-0517-2.

[73] Ruiz ML, Villanueva SSM, Luquita MG, Pellegrino JM, Rigalli JP, Arias A, et al. Induction of intestinal multidrug resistance-associated protein 2 (Mrp2) by spironolactone in rats. Eur J Pharmacol 2009;623:103-6. doi:10.1016/j.ejphar.2009.09.014.

[74] Haslam IS, Jones K, Coleman T, Simmons NL. Induction of P-glycoprotein expression and function in human intestinal epithelial cells (T84). Biochem Pharmacol 2008;76:85061. doi:10.1016/j.bcp.2008.07.020.

[75] Martin P, Riley R, Back DJ, Owen A. Comparison of the induction profile for drug disposition proteins by typical nuclear receptor activators in human hepatic and intestinal cells. Br J Pharmacol 2008;153:805-19. doi:10.1038/sj.bjp.0707601.

[76] Theile D, Allendorf D, Köhler B, Jassowicz A, Weiss J. Obatoclax as a perpetrator in drug-drug interactions and its efficacy in multidrug resistance cell lines. J Pharm Pharmacol 2015;67:1575-84. doi:10.1371/journal.pone.0136080.

[77] Ebert B, Kisiela M, Wsól V, Maser E. Proteasome inhibitors MG-132 and bortezomib induce AKR1C1, AKR1C3, AKR1B1, and AKR1B10 in human colon cancer cell lines SW-480 and HT-29. Chem Biol Interact 2011;191:239-49. doi:10.1016/j.cbi.2010.12.026.

[78] Aleksunes LM, Goedken MJ, Rockwell CE, Thomale J, Manautou JE, Klaassen CD. Transcriptional regulation of renal cytoprotective genes by Nrf2 and its potential use as a therapeutic target to mitigate cisplatin-induced nephrotoxicity. J Pharmacol Exp Ther 2010;335:2-12. doi:10.1124/jpet.110.170084.

[79] Ghanem CI, Rudraiah S, Bataille AM, Vigo MB, Goedken MJ, Manautou JE. Role of nuclear factor-erythroid 2-related factor 2 (Nrf2) in the transcriptional regulation of brain ABC transporters during acute acetaminophen (APAP) intoxication in mice. Biochem Pharmacol 2015;94:203-11. doi:10.1016/j.bcp.2015.01.013.

[80] Sestili P, Fimognari C. Cytotoxic and antitumor activity of sulforaphane: the role of reactive oxygen species. Biomed Res Int 2015; 2015:1-9.

[81] Traka M, Gasper AV., Smith JA, Hawkey CJ, Bao Y, Mithen RF. Transcriptome analysis of human colon Caco-2 cells exposed to sulforaphane. J Nutr 2005;135:1865-72.

[82] Jakubíková J, Sedlák J, Mithen R, Bao Y. Role of PI3K/Akt and MEK/ERK signaling pathways in sulforaphane- and erucin-induced phase II enzymes and MRP2 transcription, G2/M arrest and cell death in Caco-2 cells. Biochem Pharmacol 2005;69:1543-52. doi:10.1016/j.bcp.2005.03.015. 
[83] Harris KE, Jeffery EH. Sulforaphane and erucin increase MRP1 and MRP2 in human carcinoma cell lines. J Nutr Biochem 2008;19:246-54. doi:10.1016/j.jnutbio.2007.02.014.

[84] Wang X, Campos CR, Peart JC, Smith LK, Boni JL, Cannon RE, et al. Nrf2 up-regulates ATP binding cassette transporter expression and activity at the blood-brain and bloodspinal cord barriers. J Neurosci 2014;34:8585-93. doi:10.1523/JNEUROSCI. 2935-13.2014.

[85] Bock KW, Eckle T, Ouzzine M, Fournel-Gigleux S. Coordinate induction by antioxidants of UDP-glucuronosyltransferase UGT1A6 and the apical conjugate export pump MRP2 (multidrug resistance protein 2) in Caco-2 cells. Biochem Pharmacol 2000;59:467-70. doi:10.1016/S0006-2952(99)00366-4.

[86] Jia Y, Liu Z, Huo X, Wang C, Meng Q, Liu Q, et al. Enhancement effect of resveratrol on the intestinal absorption of bestatin by regulating PEPT1, MDR1 and MRP2 in vivo and in vitro. Int J Pharm 2015;495:588-98. doi:10.1016/j.ijpharm.2015.09.042.

[87] Sane RS, Steinmann GG, Huang Q, Li Y, Podila L, Mease K, et al. Mechanisms underlying benign and reversible unconjugated hyperbilirubinemia observed with faldaprevir administration in hepatitis C virus patients. J Pharmacol Exp Ther 2014;351:40312. doi:10.1124/jpet.114.218081.

[88] Kiser JJ, Burton Jr JR, Everson GT. Drug-drug interactions during antiviral therapy for chronic hepatitis C. Nat Rev Gastroenterol Hepatol 2013;10:596-606. doi:10.1038/ nrgastro.2013.106.Drug.

[89] Arias A, Villanueva SSM, Ruiz ML, Luquita MG, Veggi LM, Pellegrino M, et al. Regulation of expression and activity of rat intestinal multidrug resistance-associated protein 2 by cholestatic estrogens. Drug Metab Dispos 2009;37:1277-85. doi:10.1124/ dmd.108.025643.thus.

[90] Arias A, Rigalli JP, Villanueva SSM, Ruiz ML, Luquita MG, Perdomo VG, et al. Regulation of expression and activity of multidrug resistance proteins MRP2 and MDR1 by estrogenic compounds in Caco-2 cells. Role in prevention of xenobiotic-induced cytotoxicity. Toxicology 2014;320:46-55. doi:10.1016/j.tox.2014.03.007.

[91] Edvardsson K, Nguyen-Vu T, Kalasekar SM, Pontén F, Gustafsson J-A, Williams C. Estrogen receptor B expression induces changes in the microRNA pool in human colon cancer cells. Carcinogenesis 2013;34:1431-41. doi:10.1093/carcin/bgt067.

[92] Haenisch S, Laechelt S, Bruckmueller H, Werk A, Noack A, Bruhn O, et al. Downregulation of ATP-binding cassette $\mathrm{C} 2$ protein expression in HepG2 cells after rifampicin treatment is mediated by microRNA-379. Mol Pharmacol 2011;80:314-20. doi: 10.1124/mol.110.070714.

[93] Jäger W, Winter O, Halper B, Salamon A, Sartori M, Gajdzik L, et al. Modulation of liver canalicular transport processes by the tyrosine-kinase inhibitor genistein: implications 
of genistein metabolism in the rat. Hepatology 1997;26:1467-76. doi:10.1053/jhep. 1997.v26.pm0009397986.

[94] Yokooji T, Kawabe Y, Mori N, Murakami T. Effect of genistein, a natural soy isoflavone, on the pharmacokinetics and intestinal toxicity of irinotecan hydrochloride in rats. J Pharm Pharmacol 2013;65:280-91. doi:10.1111/j.2042-7158.2012.01592.x.

[95] Naruhashi K, Tamai I, Inoue N, Muraoka H, Sai Y, Suzuki N, et al. Involvement of multidrug resistance-associated protein 2 in intestinal secretion of grepafloxacin in rats. Antimicrob Agents Chemother 2002;46:344-9. doi:10.1128/AAC.46.2.344-349.2002.

[96] El-Sheikh AAK, van den Heuvel JJMW, Koenderink JB, Russel FGM. Interaction of nonsteroidal anti-inflammatory drugs with multidrug resistance protein (MRP) 2/ ABCC2-and MRP4/ABCC4-mediated methotrexate transport. J Pharmacol Exp Ther 2007;320:229-35. doi:10.1124/jpet.106.110379.ceiving.

[97] Dahan A, Amidon GL. MRP2 mediated drug-drug interaction: indomethacin increases sulfasalazine absorption in the small intestine, potentially decreasing its colonic targeting. Int J Pharm 2010;386:216-20. doi:10.1016/j.ijpharm.2009.11.021.

[98] Lindahl A, Sjöberg A, Bredberg U, Toreson H, Ungell A-L, Lennernäs H. Regional intestinal absorption and biliary excretion of fluvastatin in the rat: possible involvement of mrp2. Mol Pharm 2004;1:347-56. doi:10.1021/mp0499297.

[99] Dahan A, Sabit H, Amidon GL. Multiple efflux pumps are involved in the transepithelial transport of colchicine: Combined effect of P-glycoprotein and multidrug resistance- associated protein 2 leads to decreased intestinal absorption throughout the entire small intestine. Drug Metab Dispos 2009;37:2028-36. doi:10.1124/dmd.109.028282. 